\title{
Investigation the Effects of Cutting Parameters on Geometric Accuracy of Machining Marine Propeller using 3D Photo-scanning Technique
}

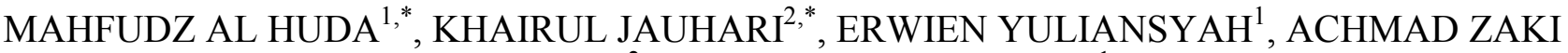 \\ RAHMAN $^{2}$, ENDARTO TRI WIBOWO ${ }^{1}$ \\ ${ }^{1}$ Center for Technology of Machinery Industry (PTIP), Agency for the Assessment and Application \\ Technology (BPPT), PUSPIPTEK, Tangerang Selatan, INDONESIA \\ ${ }^{2}$ Center for Technology of Machine Tools, Production and Automation (BTMEPPO), Agency for the \\ Assessment and Application Technology (BPPT), PUSPIPTEK, Tangerang Selatan, INDONESIA
}

\begin{abstract}
The measurement method and analysis experiences of 3D scanning instrument used in manufacturing industry is a novel for recent company before we are going to apply the 4.0 industrial era. The research purpose is to provide a measurement and analysis results of quality control and product improvement stage in the third industrial era. This paper presents an approach for accuracy measurement of complete scanning complex geometric of marine propeller blades. The geometric accuracy of marine propeller models, which has been finished by machining processes are measured using 3D photo-scanning technique. The effects of cutting parameters, that is step-overs and feed-rates, on the geometric accuracy are investigated. Inspection of geometric accuracy is performed by comparing the result of 3D scanning measurement of finished propeller with CAD design data. The results showed that greater step-over value, the deviation value tends to be smaller. Similar to the feed-rates, greater value of the feed-rates, the deviation value tends to be smaller.
\end{abstract}

Key-Words: - 3D photo-scanning, geometric accuracy, marine propeller, machining processes

Received: September 13, 2019. Revised: January 17, 2020. Accepted: January 23, 2020.

Published: January 31, 2020.

\section{Introduction}

The need for 3D Scanning instruments is inseparable from the needs that are so fast and effective in costs and the increasing need for measuring the accuracy of a small-sized manufacturing component. As a result of the many needs of these small-sized components, a car eful and accurate method is needed. in measurement [1]. The use of an ultra-precision milling machine is capable of producing component accuracy under micron meter units [2]. In many products, for example mold or electric discharge machine devices (EDM) is not only the accuracy of linear and angular measurements that are important, but the quality and precision of 3D complexity of objects is also important $[3,4]$. Therefore, object metrology requirements can be achieved by adopting several methods [5].

In It has been shown that several current technology models [6] used for complex 3D surfaces include, for computer X-ray tomography methods are not only often used for non-destructive tests on material defect inspections [6] but are also widely used in various Micro and Nano-metrology applications [7 - 11]. For the method of Coordinate measuring machines (CMM), using touch and optic probing is also widely used for the purpose of complex 3D surfaces. However, this method has many limitations including touch probes which can damage subtle parts at the point of contact, and the speed of actualization for digitization is very limited [12 - 14]. In addition, optical probing in CMM has limitations in measuring the surface slope height so that it has poor lateral resolution due to diffraction $[14,15]$. CMM is quite expensive and large in size so that recently developed some of the latest models that are more economical and compact models [16, 17]. Based on the above review, it is clear that CMMS and X-ray tomography cannot naturally restore the object's 3D texture model.

In the past, photogrammetry was not considered capable of scanning and measuring small parts of a complex surface object [6]. For the time being [18, 19], on the contrary, it is possible to use photogrammetry to scan 3D accurately from a small object even to sub-millimeter scales [20]. Several factors have been analyzed based on the accuracy and precision of small objects using digital photogrammetry at a close distance [21].

The measurement method and analysis experiences of 3D scanning instrument used in manufacturing industry is a novel for recent company before we are going to apply the 4.0 industrial era. The research purpose is to provide a measurement and analysis results of quality control and product improvement stage in the third 
industrial era. In this study, the measurement of geometric accuracy of marine propeller models, which has been finished by machining processes, is performed using 3D Photo-scanning Technique. The effects of cutting parameters, that is step-over and feed-rate, on the geometric accuracy are investigated. The results showed that greater stepover and feed-rate values, these deviation values tend to be smaller.

\section{Methods}

\subsection{Camera Calibration}

Algorithms from digital photogrammetry basically require two types of calibration: external and internal. External calibration is a procedure that gives the spatial position of the camera sensor, while internal allows radial distortion and decentering of the lens to be compensated [23, 24]. Both calibrations can be estimated automatically by many software or obtained by special calibration procedures. The calibration was able to investigate possibilities for obtaining a 1: 1 digital 3D model. In this study to eliminate manufacturing and assembly inaccuracies, external calibration was carried out in the initial phase through acquisition with a $50 \mathrm{~mm} x$ $30 \mathrm{~mm}$ planar calibration pattern, with a 12-bit code target.

In Fig. 1, the target code has a little black circle in the center, which allows to measure the coordinates of each target. For this purpose, Brownshape 400 opt ical CMM has been used (accuracy in $\mathrm{X}=5.33 \mu \mathrm{m}, \mathrm{Y}=5.33 \mu \mathrm{m}, \mathrm{Z}=4.33$ $\mu \mathrm{m})$.

The calibrator images that have been obtained will be translated through image-based 3D modeling software [22]. The software is based on the Structure-From-Motion (SFM) and Dense MultiView 3D Reconstruction algorithms (DMVR) allowing to create 3D models of collections of images that are not sequential in order to describe scenes, or objects, from different points of view [25]. In the first step the software aligns the image, on the basis of point cloud on the source photo, and matches it with the SIFT (scale invariant transform feature) like the approach [26]. In this step, the coordinates that have been previously measured from the target code are automatically marked by the software, then the actual camera position in 3D space is calculated for each shot. With the explanation of the above method, it is possible to state that the camera's position in space is constant and does not depend on the time function, so that it can be used to construct digitally 3D models of object objects that will not being scanned.

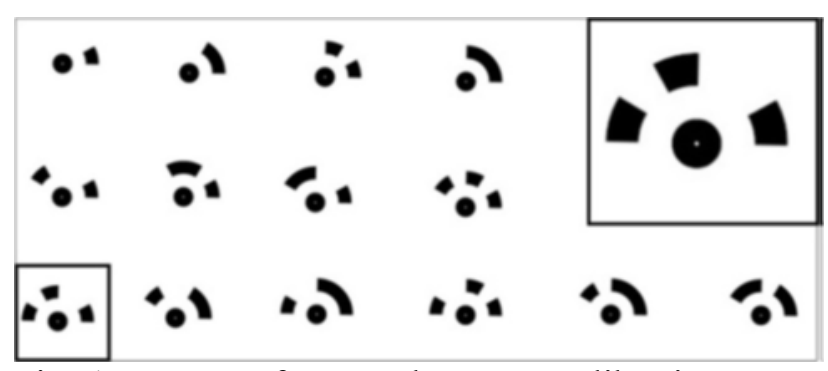

Fig. 1. Pattern of external camera calibration target code

\subsection{Scanning Procedure}

The calibrator images that have been obtained will be translated through image-based 3D modeling software [22]. The software is based on the Structure-From-Motion (SFM) and Dense MultiView 3D Reconstruction algorithms (DMVR) allowing to create 3D models of collections of images that are not sequential in order to describe scenes, or objects, from different points of view [25]. In the first step the software aligns the image, on the basis of point cloud on the source photo, and matches it with the SIFT (scale invariant transform feature) like the approach [26]. In this step, the coordinates that have been previously measured from the target code are automatically marked by the software, then the actual camera position in $3 \mathrm{D}$ space is calculated for each shot. With the explanation of the above method, it is possible to state that the camera's position in space is constant and does not depend on the time function, so that it can be used to construct digitally 3D models of object objects that will not being scanned.

Photogrammetric scanning methodology has been developed to automate and develop traditional measurement techniques for the acquisition and reconstruction of photogrammetric process data. Fig. 2 shows a m easurement method model with photogrammetric scanning system (ATOS GOM) with Fixed Table (PSSFT), which is used for the implementation of experiments measuring the geometric accuracy of the marine propeller blade components (Fig. 3).

On the PSSFT measurement model, the object is placed on a fixed table (D), then a digital SLR camera is placed fixed on the platform (B), the camera can be adjusted along the rigid frame (C). The LED lighting system (E) is integrated with the camera to ensure the lighting conditions remain in homogeneous conditions.

In this system, lens selection is related to the maximum distance of the object's dimensions to the 
lens. The focal length of the lens can be fixed after setting the focus on the known distance (r) and its position adjusted by adjusting the position of camera that points to the object via a sliding platform (B).

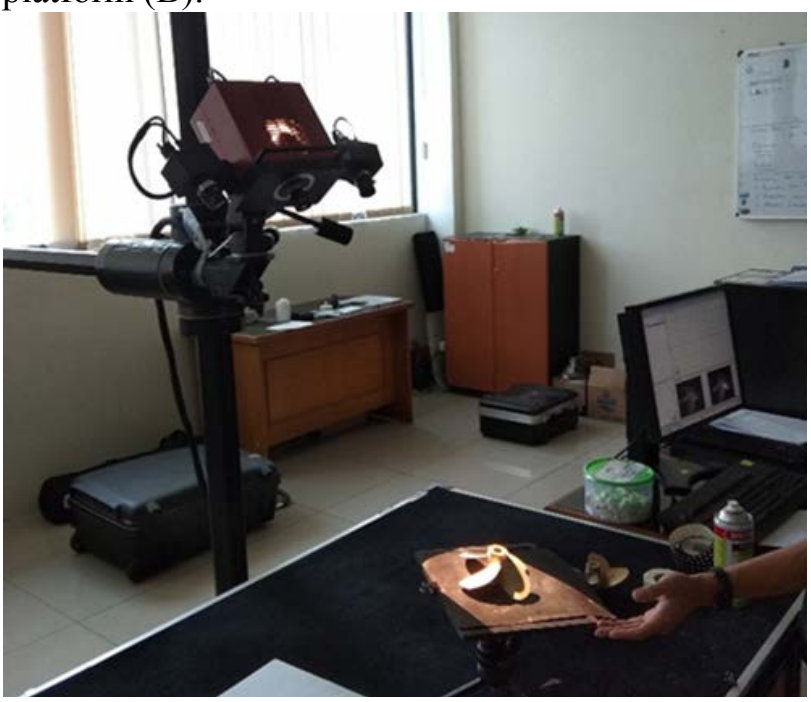

Fig. 2. 3D Photo-scanning instrument system
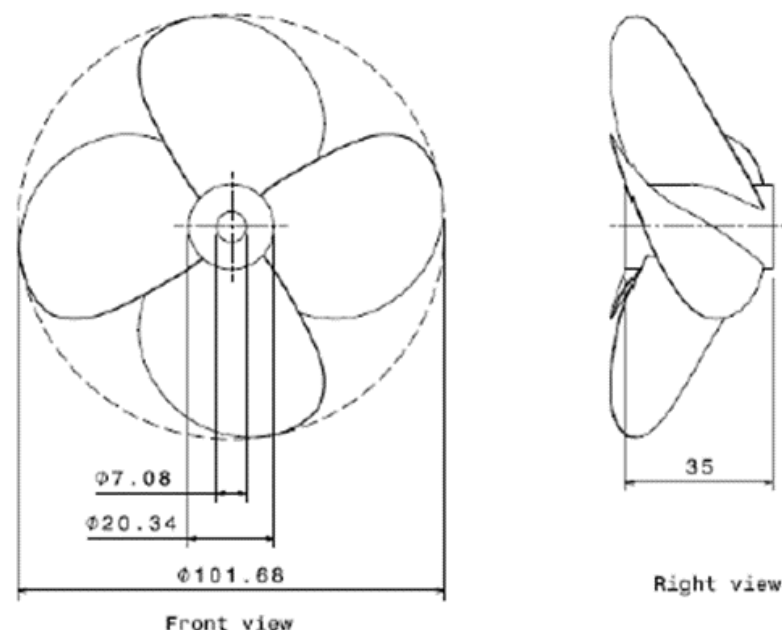

Right view

Fig. 3. Marine propeller model

The slope angle (Ø) can be set in the slope function to the surface of the scanning object, this angle can increase if there is a p revalence of horizontal surfaces (flat components), or it can be reduced if there is a prevalence of vertical surfaces (pillar components).

Once the camera position and tilt angle have been in the right position, the scanning process is done simultaneously during shooting until it is complete. Then the step angle between each step of image capture $(\theta)$ is one of the other important process parameters, where if the angle of this step is reduced then the result is a greater number of shooting frequency resulting in a large percentage of overlapping photos or images produced (in fact it can improve features such as photogrammetric reconstruction visibility and quality), but on the other hand the effect can increase the time for computer scanning and processing.

The method used to overcome the main limitations, which are related to the absence of an internal scale from the 3D model obtained from the use of photogrammetry, is to perform an external calibration for the camera.

In the data acquisition phase, it is automatically set by the computer, then the camera rotates according to the step angle until it stops, then the image is sent to the camera, and the image is then stored. This process is repeated continuously until the camera rotation stops. Then, the images obtained are elaborated using image-based 3D modeling software [22].

\subsection{Design of Experiment}

To find out the influence of key factors on the ability of 3D scanning methodology, the experimental design needs to be realized. For this purpose, the design variable has been selected. According to the literature, the following four factors were chosen: semi finish (X1), finish (X2), feeding variation (X3) and step over (X4) variations (Table 1). The highest and lowest values for each factor are determined by c onsidering the experimental setup limit in accordance with the literature, rules or SOP for acquisition of photogrammetric data and previous experience.

For each scanning process condition of the experimental plan, four data acquisition variables are collected and carried out the data collection randomly. For experimental realization in this case the Canon 40D digital SLR camera (10-megapixel effective pixel, APS-C22.2 $\mathrm{mm} 14.8 \mathrm{~mm}$ effective sensor) with a Canon EF $50 \mathrm{~mm} \mathrm{1:} \mathrm{1:} 8$ II lenses focused on infinity and Kenko Extension Tubes with a length of $36 \mathrm{~mm}$.

\section{Results and Discussions}

\subsection{Design of Experiment}

Inspection of geometric accuracy is performed by comparing the result of $3 \mathrm{D}$ scanning measurement of finished propeller with $\mathrm{CAD}$ design data.

In this method, data processing is carried out in several stages, namely tabulating data to compare 5 inspection points (sample point) at measurement position \#1 and measurement position \#2 from the front side of the propeller as shown in Tables 1 and 
2 , then determining the deviation graph plot versus step-over measurement positions \#1 and \#2 for the front side of the propeller blade as shown in Fig. 6 and 7 , and then analyze the effect of machining parameters for several step-over values on propeller blade surface deviation at measurement positions \#1 and \#2 which in this case are referred to sequentially as the outer and middle ends of the blade surface.

Table 1. Surface comparison in step-over variation for 5 inspection points in measurement position \#1

\begin{tabular}{cccc}
\hline Blade & Point & Deviation $(\mathrm{mm})$ & Step-over $(\mathrm{mm})$ \\
\hline 1 & 1 & 0.100 & 0.1 \\
\hline 2 & & 0.037 & 0.3 \\
\hline 3 & & 0.040 & 0.5 \\
\hline 4 & & 0.085 & 0.7 \\
\hline 1 & 2 & 0.104 & 0.1 \\
\hline 2 & & 0.052 & 0.3 \\
\hline 3 & & 0.044 & 0.5 \\
\hline 4 & & 0.090 & 0.7 \\
\hline 1 & 3 & 0.105 & 0.1 \\
\hline 2 & & 0.049 & 0.3 \\
\hline 3 & & 0.051 & 0.5 \\
\hline 4 & & 0.093 & 0.7 \\
\hline 1 & 4 & 0.103 & 0.1 \\
\hline 2 & & 0.049 & 0.3 \\
\hline 3 & & 0.045 & 0.5 \\
\hline 4 & & 0.083 & 0.1 \\
\hline 1 & 5 & 0.106 & 0.1 \\
\hline 2 & & 0.056 & 0.3 \\
\hline 3 & & 0.043 & 0.5 \\
\hline 4 & & 0.084 & 0.7 \\
\hline
\end{tabular}

Table 2. Surface comparison in step-over variation for 5 inspection points in measurement position \#2

\begin{tabular}{cccc}
\hline Blade & Point & Deviation $(\mathrm{mm})$ & Step-over $(\mathrm{mm})$ \\
\hline 1 & 1 & 0.077 & 0.1 \\
\hline 2 & & 0.036 & 0.3 \\
\hline 3 & & 0.016 & 0.5 \\
\hline 4 & & 0.052 & 0.7 \\
\hline 1 & 2 & 0.083 & 0.1 \\
\hline 2 & & 0.037 & 0.3 \\
\hline 3 & & 0.013 & 0.5 \\
\hline 4 & & 0.053 & 0.7 \\
\hline 1 & 3 & 0.081 & 0.1 \\
\hline 2 & & 0.038 & 0.3 \\
\hline 3 & & 0.010 & 0.5 \\
\hline 4 & & 0.049 & 0.7 \\
\hline 1 & 4 & 0.095 & 0.1 \\
\hline 2 & & 0.037 & 0.3 \\
\hline 3 & & 0.037 & 0.5 \\
\hline 4 & & 0.052 & 0.1 \\
\hline 1 & 5 & 0.082 & 0.1 \\
\hline 2 & & 0.041 & 0.3 \\
\hline 3 & & 0.026 & 0.5 \\
\hline 4 & & 0.061 & 0.7 \\
\hline
\end{tabular}

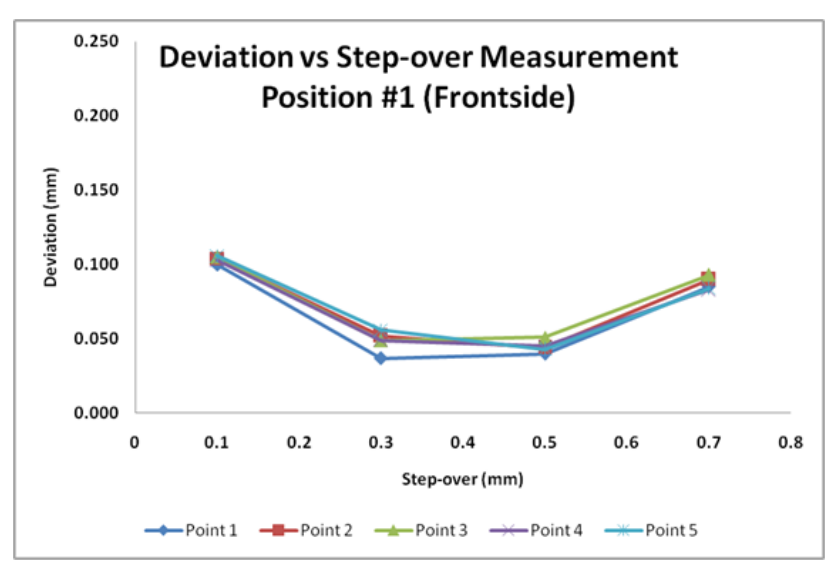

Fig. 6. Comparison chart of step-over effect on surface deviation for 5 sample points for measurement position \#1 on the front side of the blade propeller.

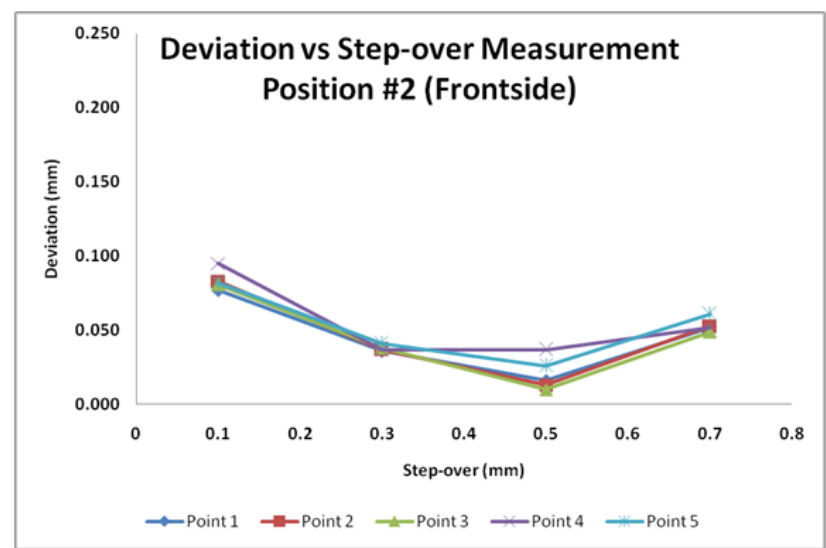

Fig. 7. Comparison chart of step-over effect on surface deviation for 5 sample points for measurement position $\# 2$ on the front side of the blade propeller.

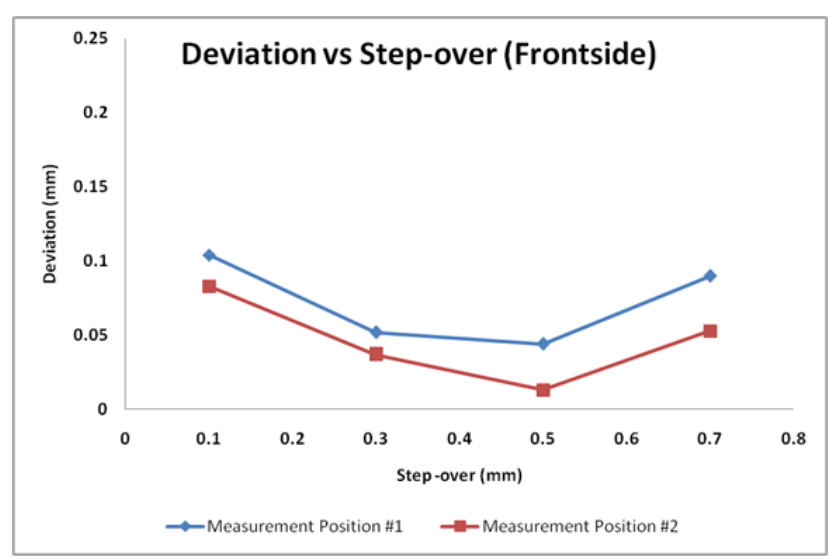

Fig. 8. Graph of comparison of step-over effect on surface deviation for sample point 2 be tween measurement position \#1 and \#2 on the front side of the blade propeller for variations in step-over parameters.

In Appendix Fig. 4 and 5, almost all section of the propeller contours is yellow to green, indicating 
that most of the size of the propeller blades is in accordance with the design made. The red color in the out-end of the blade is caused by differences in radius in the area. This is very natural, because the radius is formed as a result of the radius cutter used. The difference in shape and size on this base does not affect the performance of the propeller.

In Fig. 6, it can be seen that for data collection of 5 sample points in measurement position \#1 (frontside) in general the tendency of a low deviation value occurs in step-over $0.3 \mathrm{~mm}$ and 0.5 $\mathrm{mm}$ this is because the step-over value conditions are effective for the cutting force process or better feeding when in the curvature area of the blade profile.

Likewise what happens in Fig. 7 shows that for data collection of $5 \mathrm{~s}$ ample points in position measurement \#2 (frontside) in general the tendency for a low deviation value to occur in a step-over 0.3 $\mathrm{mm}$ and $0.5 \mathrm{~mm}$ is because the step-over value condition is effective for the process better cutting force or feeding when in the curvature area of the blade profile.

In whole analyzing data of the effect of machining parameters for several step-over values, namely $(0.1,0.3,0.5$, and 0.7$)$ on the propeller blade surface deviation at measurement positions \#1 (frontside) and position \#2 (frontside) are compared.

Based on the graph in Fig. 8, it is shown that for both measurement points \#1 and \#2 in this case the sample point no. 2 (Tables 1 and 2), in general the deviation of the surface comparison with the lowest value occurs in the step-over of $0.5 \mathrm{~m} \mathrm{~m}$ to 0.044 $\mathrm{mm}$ at the measurement position \#1 and $0.013 \mathrm{~mm}$ at the measurement position \#2. From the graph it can also be explained that at position measurement \#2 tends to have a lower trend of surface deviation when compared to position measurement \#1 for all step-over values, this is caused by the higher material profile stiffness in the measurement position \#2 if the position of measurement \#1 is compared so that it causes a better cutting or feeding style by tooling on the machining process.

\subsection{The Effect of feed-rate}

In appendix Fig 9 and 10, almost all parts of the propeller are red, indicating that most of the size of the propeller blades are out accordance with the design made. The red color in the base of the blade is caused by differences in radius in the area. This is very natural, because the radius is formed as a result of the radius cutter used. The difference in shape and size on this base does not affect the performance of the propeller.
Table 3. Surface comparison in feed-rate variations for 5 inspection points in measurement position \#1

\begin{tabular}{cccc}
\hline Blade & Point & $\begin{array}{c}\text { Deviation } \\
(\mathrm{mm})\end{array}$ & $\begin{array}{c}\text { Feed-rate } \\
(\mathrm{mm} / \mathrm{min})\end{array}$ \\
\hline 1 & 1 & 0.233 & 100 \\
\hline 2 & & 0.101 & 200 \\
\hline 3 & & 0.077 & 300 \\
\hline 4 & & 0.167 & 400 \\
\hline 1 & 2 & 0.232 & 100 \\
\hline 2 & & 0.110 & 200 \\
\hline 3 & & 0.077 & 300 \\
\hline 4 & & 0.170 & 400 \\
\hline 1 & 3 & 0.231 & 100 \\
\hline 2 & & 0.117 & 200 \\
\hline 3 & & 0.076 & 300 \\
\hline 4 & & 0.170 & 400 \\
\hline 1 & 4 & 0.238 & 100 \\
\hline 2 & & 0.116 & 200 \\
\hline 3 & & 0.069 & 300 \\
\hline 4 & & 0.166 & 400 \\
\hline 1 & 5 & 0.223 & 100 \\
\hline 2 & & 0.120 & 200 \\
\hline 3 & & 0.075 & 300 \\
\hline 4 & & 0.171 & 400 \\
\hline & &
\end{tabular}

Table 4. Surface comparison in feed-rate variations for 5 inspection points in measurement position \#2

\begin{tabular}{cccc}
\hline Blade & Point & $\begin{array}{c}\text { Deviation } \\
(\mathrm{mm})\end{array}$ & $\begin{array}{c}\text { Feed-rate } \\
(\mathrm{mm} / \mathrm{min})\end{array}$ \\
\hline 1 & 1 & 0.170 & 100 \\
\hline 2 & & 0.045 & 200 \\
\hline 3 & & 0.087 & 300 \\
\hline 4 & & 0.172 & 400 \\
\hline 1 & 2 & 0.172 & 100 \\
\hline 2 & & 0.059 & 200 \\
\hline 3 & & 0.077 & 300 \\
\hline 4 & & 0.178 & 400 \\
\hline 1 & 3 & 0.181 & 100 \\
\hline 2 & & 0.072 & 200 \\
\hline 3 & & 0.070 & 300 \\
\hline 4 & & 0.177 & 400 \\
\hline 1 & 4 & 0.186 & 100 \\
\hline 2 & & 0.067 & 200 \\
\hline 3 & & 0.084 & 300 \\
\hline 4 & & 0.176 & 400 \\
\hline 1 & 5 & 0.161 & 100 \\
\hline 2 & & 0.051 & 200 \\
\hline 3 & & 0.085 & 300 \\
\hline 4 & & 0.168 & 400 \\
\hline
\end{tabular}

With this method, data processing is carried out in several stages, namely tabulating data to compare 5 inspection points (sample point) at measurement position \#1 and measurement position \#2 from the front side of the propeller blade as shown in Tables 3 and 4, determining the deviation graph plot versus feed-rate measurement positions \#1 and \#2 for the 
front side of the propeller blade as shown in Fig. 11 and 12, then analyze the effect of machining parameters for several feed-rate values on the blade propeller blade surface deviation at measurement positions \#1 and \#2 which in this case sequentially referred to as the outer and middle ends of the blade surface.

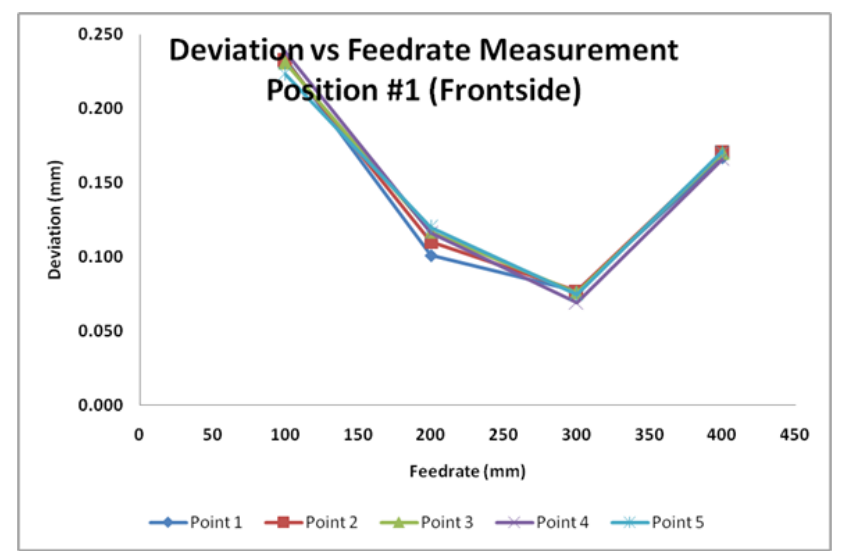

Fig. 11. Comparison chart of the effect of feed-rate to surface deviation to 5 sample points for measurement position $\# 1$ on the front side of the blade propeller.

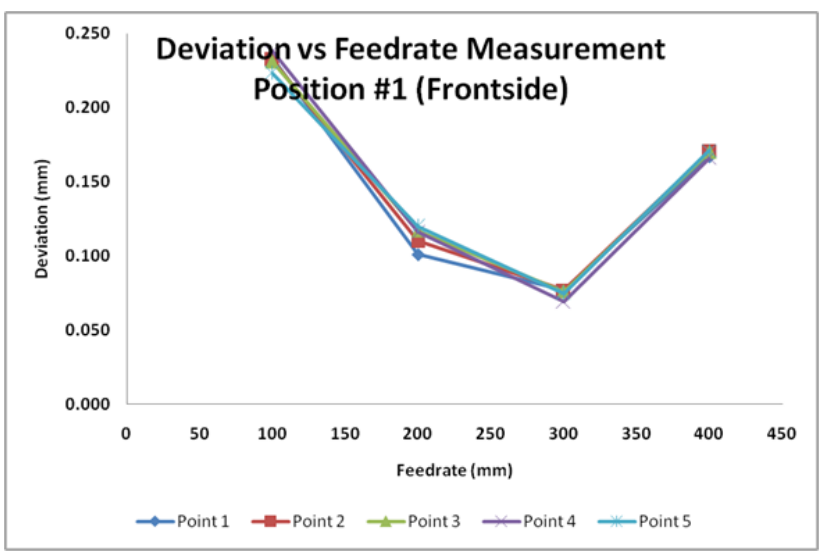

Fig. 12. Comparison chart of the effect of feed-rate to surface deviation to 5 sample points for measurement position \#2 on the front side of the blade propeller.

Based on the graph in Fig. 13, it is shown that for both measurement points \#1 and \#2 in this case the sample point no. 2 (Tables 3 and 4), in general the deviation of the surface ratio with the lowest value occurs at the feed-rate of $300 \mathrm{~mm} / \mathrm{min}$ to $0.077 \mathrm{~mm}$ at position measurement $\# 1$ and the feed-rate of 200 $\mathrm{mm} / \mathrm{min}$ to $0.059 \mathrm{~mm}$ at the measurement position \#2. From the graph it can also be explained that there is a tendency for the deviation to decrease as the feed-rate value increases but the feed-rate of 200 $\mathrm{mm} / \mathrm{min}$ and $300 \mathrm{~m} \mathrm{~m} / \mathrm{min}$ is more suitable for profile curvature characteristics and at position measurement \#2 tends to have a lower trend of surface deviation compared to the measurement \#1 for all feed-rate values, this is caused by the higher material profile stiffness in position measurement \#2 if compared to measurement position $\# 1$ so that it causes better cutting or feeding forces by tooling on the machining process.

Based on the both previous explanation it can be concluded that the greater step-over value, the deviation value tends to be smaller. Similar to the feed-rates, the greater value of feed-rates, the deviation value tends to be smaller too.

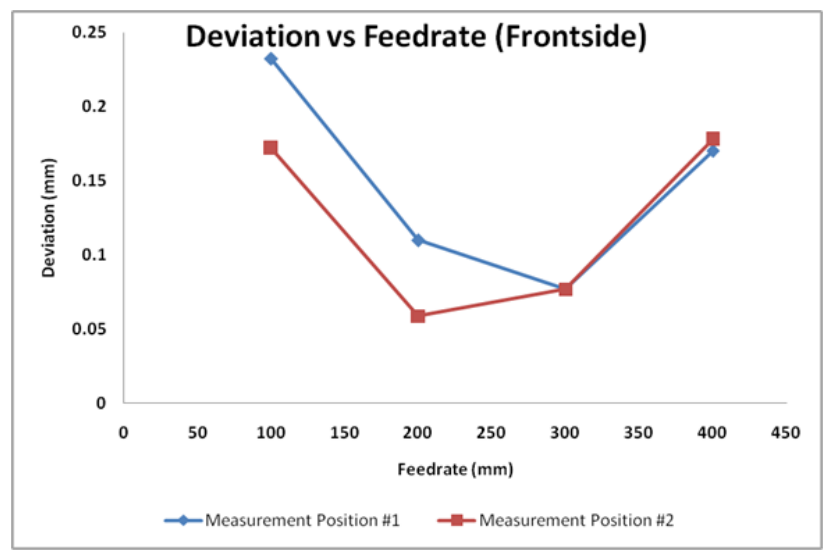

Fig. 13. The graph comparison of the effect of feedrate to surface deviation for sample point 2 between measurement position $\# 1$ and $\# 2$ on the front side of the blade propeller for variations in feed-rate parameters.

\section{Conclusion}

In this paper, geometric accuracy of marine propeller models, which has been finished by machining processes are measured using $3 \mathrm{D}$ photoscanning technique. Inspection of geometric accuracy is performed by comparing the result of 3D scanning measurement of finished propeller with CAD design data. The measurement method applied in this study is effective for measuring the geometric accuracy of the propeller blade surface. The effect of machining parameters for several step-over and feed-rate values, on the propeller blade surface deviation at measurement positions \#1 (frontside) and position \#2 (frontside) are compared. For the step-over parameters, the deviation of the surface comparison with the lowest value occurs in the stepover $0.5 \mathrm{~m} \mathrm{~m}$ to $0.044 \mathrm{~mm}$ at the measurement position $\# 1$ and $0.013 \mathrm{~mm}$ at the measurement position \#2. A nd for the feed-rate parameters, the deviation of the surface ratio with the lowest value occurs at the feed-rate of $300 \mathrm{~mm} / \mathrm{min}$ to $0.077 \mathrm{~mm}$ at position measurement $\# 1$ and the feed-rate of 200 
$\mathrm{mm} / \mathrm{min}$ to $0.059 \mathrm{~mm}$ at the measurement position \#2. Based on the graph comparison of the effects of step-over and feed-rate, it can also be explained that at position measurement $\# 2$ tends to have a lower trend of surface deviation when compared to position measurement \#1 for all step-over and feedrate values, this is caused by the higher material profile stiffness in the measurement position \#2 if the position of measurement \# 1 is compared so that it causes a better cutting or feeding style by tooling on the machining process.

\section{Conflicts of Interest:}

The authors declare no conflict of interest.

\section{Acknowledgements:}

This paper was funded by an incentive research grant from Ministry of Research, Technology and Higher Education of the Republic Indonesia, which the authors gratefully acknowledge. All authors contributed equally to this work. All authors discussed the results and implication and commented on the manuscript at all stages.

\section{References:}

[1] C.K. Malek, and V. Saile, "Applications of LIGA Technology to Precision Manufacturing of High-Aspect-Ratio MicroComponents and -Systems: A Review," Microelectronics Journal, vol. 35, no. 2, 2004, pp. 131-143.

[2] Y. Qin, A. Brockett, Y. Ma, A. Razali, J. Zhao, C. Harrison, "Micro-Manufacturing: Research, Technology Outcomes and Development Issues," International Journal of Advanced Manufacturing Technology, vol. 47, no. 9-12, 2009, pp. 821-837.

[3] W. Bauer, R. Knitter, A. Emde, G. Bartelt, D. Göhring, E. Hansjosten, "Replication Techniques for Ceramic Micro-Components with High Aspect Ratios," Microsystem Technologies, vol. 9, no. 1-2, 2002, pp. 81-86.

[4] G. Byrne, D. Dornfeld, B. Denkena, "Advancing Cutting Technology," CIRP Annals - Manufacturing Technology, vol. 52, no. 2, 2003, pp. 483-507.

[5] H. N. Hansen, K. Carneiro, H. Haitjema, L. De Chiffre, "Dimensional Micro and Nano Metrology," CIRP Annals - Manufacturing Technology, vol. 55, no. 2, 2006, pp. 721-743.

[6] E. Savio, L. De Chiffre, R. Schmitt, "Metrology of Freeform Shaped Parts," CIRP
Annals - Manufacturing Technology, vol. 56, no. 2, 2007, pp. 810-835.

[7] M. Dierick, L. Van Hoorebeke, P. Jacobs, B. Masschaele, J. Vlassenbroeck, V. Cnudde, "The Use of 2D Pixel Detectors in Micro- and Nano-CT Applications," Nuclear Instruments and Methods in Physics Research Section A Accelerators Spectrometers Detectors and Associated Equipment, vol. 591, no. 1, 2008, pp. 255-259.

[8] R. F. Fisher, D. E. Hintenlang, "Micro-CT Imaging of MEMS Components," Journal of Nondestructive Evaluation, vol. 27, no. 4, 2008, pp. 115-125.

[9] S. T. Ho, D. W. Hutmacher, "A Comparison of Micro CT with Other Techniques Used in the Characterization of Scaffolds," Biomaterials vol. 27, no. 8, 2006, pp. 1362-1376.

[10] Z. Wu, Z. Li, W. Huang, H. Gong, Y. Gao, J. Deng, "Comparisons of Nozzle Orifice Processing Methods Using Synchrotron X-Ray Micro-Tomography," Journal of Zhejiang University SCIENCE A, vol. 13, no. 3, 2012, pp. 182-188.

[11] P. Yang, T. Takamura, S. Takahashi, K. Takamasu, O. Sato, S. Osawa S, "Development of High-Precision Micro-Coordinate Measuring Machine: Multi- Probe Measurement System for Measuring Yaw And Straightness Motion Error of XY Linear Stage," Precision Engineering, vol. 35, no. 3, 2011, pp. 424-430.

[12] F. Meli, A. Küng, "AFM Investigation on Surface Damage Caused by Mechanical Probing with Small Ruby Spheres," Measurement Science and Technology, vol. 18, no. 2, 2007, pp. 496-502.

[13] W. P. Vliet, P. H. Van. Schellekens, "Accuracy Limitations of Fast Mechanical Probing," CIRP Annals - Manufacturing Technology, vol. 45, no. 1, 1996, pp. 483-487.

[14] J. Hoffmann, A. Weckenmann, Z. Sun, "Electrical Probing for Dimensional Micro Metrology," CIRP Annals - Manufacturing Technology, vol. 1 no. 1, 2008, pp. 59-62.

[15] H. Schwenke, U. Neuschaefer-Rube, T. Pfeifer, H. Kunzmann, "Optical Methods for Dimensional Metrology in Production Engineering," CIRP Annals - Manufacturing Technology, vol. 51, no. 2, 2002, pp. 685-699.

[16] C. S. Goo, M. B. G. Jun, A. Saito, "Probing System for Measurement of Micro- Scale Components," Journal of Manufacturing Processes, vol. 14, no. 2, 2012, pp. 174-180.

[17] K. C. Fan, Y. T. Fei, X. F. Yu, Y. J. Chen, W. L. Wang, F. Chen, "Development of a Low- 
Cost Micro-CMM for 3D Micro/Nano Measurements," Measurement Science and Technology, vol. 17, no. 3, 2006, pp. 524-532.

[18] C. Nguyen, D. Lovell, R. Oberprieler, D. Jennings, M. Adcock, E. Gates-Stuart, "Virtual 3D Models of Insects for Accelerated Quarantine Control," IEEE Int. Conf. Comput. Vis. Work., IEEE, 2013, pp. 161-167.

[19] C. V. Nguyen, D. R. Lovell, M. Adcock, J. La Salle, "Capturing Natural-Colour 3D Models of Insects for Species Discovery and Diagnostics," PLOS ONE, vol. 9, no. 4, 2014, pp. 43-46.

[20] L. M. Galantucci, F. Lavecchia, G. Percoco, "Multistack Close Range Photogrammetry for Low Cost Submillimeter Metrology," Journal of Computing and Information Science in Engineering, vol. 13, no. 4, 2013, pp. 44-50.

[21] L. M. Galantucci, G. Percoco, R. Ferrandes, "Accuracy Issues of Digital Photogrammetry for 3D Digitization of Industrial Products," Revue Internationale D'ingénierie Numérique, vol. 2, no. 1-2, 2006, pp. 29-40.

[22] "Agisoft, Photoscan Professional Edition," https://www.agisoft.com/features/professionaledition/, Jan 15, 2019.

[23] O. Sinram, M. Ritter, S. Kleindick, A. Schertel, H. Hohenberg, J. Albertz, "Calibration of an SEM, Using a Nano Positioning Tilting Table and A Microscopic Calibration Pyramid," International Archives of the Photogrammetry Remote Sensing, vol. 34, no. 5, 1976, pp. 210 215.

[24] D. C., Brown, "Close-Range Camera Calibration," Photogrammetric Engineering, 1971, pp. 855-866.

[25] A. Koutsoudis, B. Vidmar, G. Ioannakis, F. Arnaoutoglou, G. Pavlidis, C. Chamzas, "Multi-Image 3D Reconstruction Data Evaluation," Journal of Cultural Heritage, vol. 15, no. 1, 2014, pp. 73-79.

[26] D. G. Lowe, "Distinctive Image Features from Scale-Invariant Key points," International Journal of Computer Vision, vol. 60, no. 2, 2004, pp. 91-110. 


\section{Appendix}

Propeller 3 Front Side

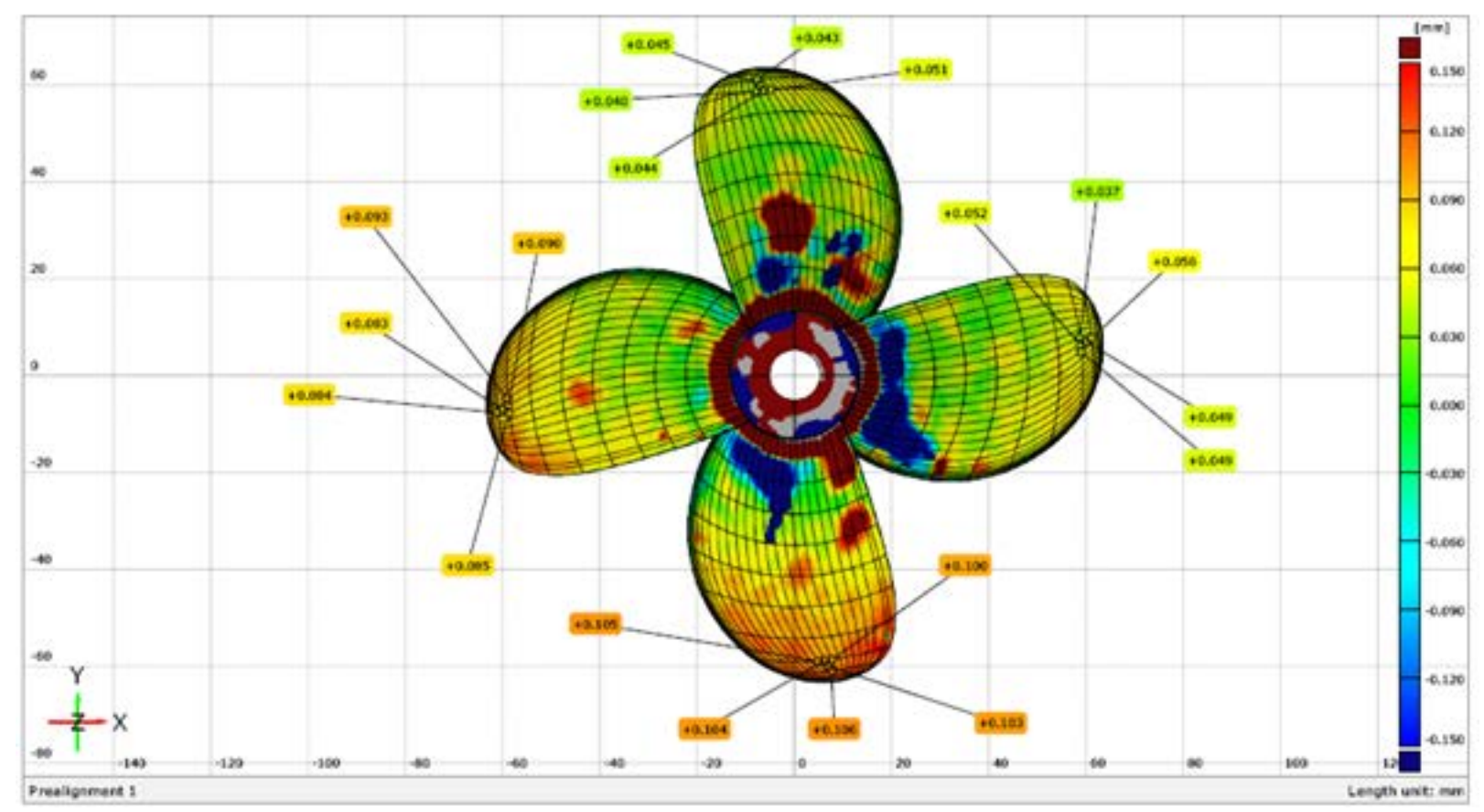

Fig. 4. Deviation contour for measurement position $\# 1$ on the front side of the blade propeller for variations in step-over parameters

\section{Propeller 3 Front Side}

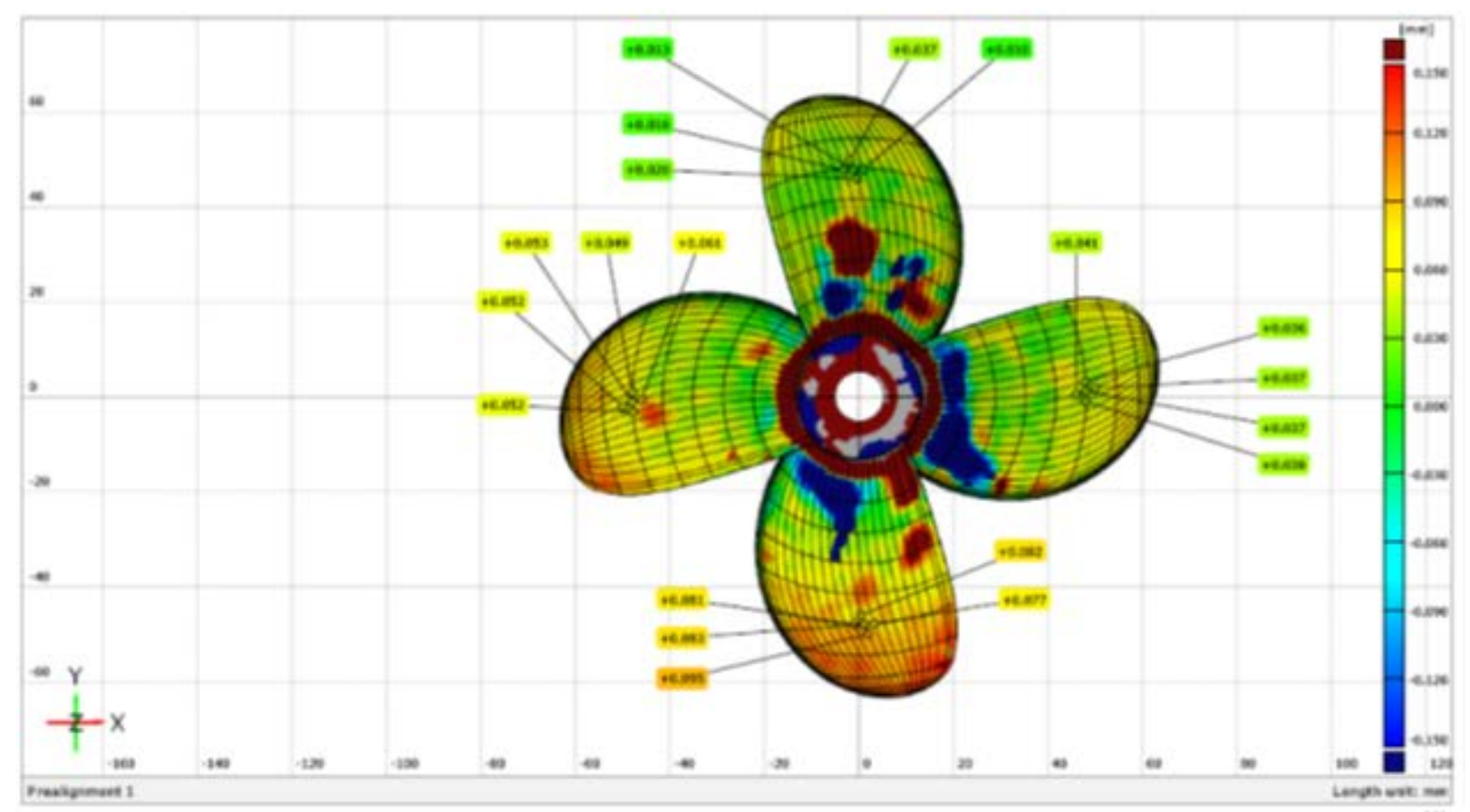

Fig. 5. Deviation contour for measurement position \#2 on the front side of the blade propeller for variations in step-over parameters 
WSEAS TRANSACTIONS on APPLIED and THEORETICAL MECHANICS DOI: $10.37394 / 232011.2020 .15 .1$
Mahfudz Al Huda, Khairul Jauhari, Erwien Yuliansyah, Achmad Zaki Rahman,

Endarto Tri Wibowo

Propeller 4 Front Side

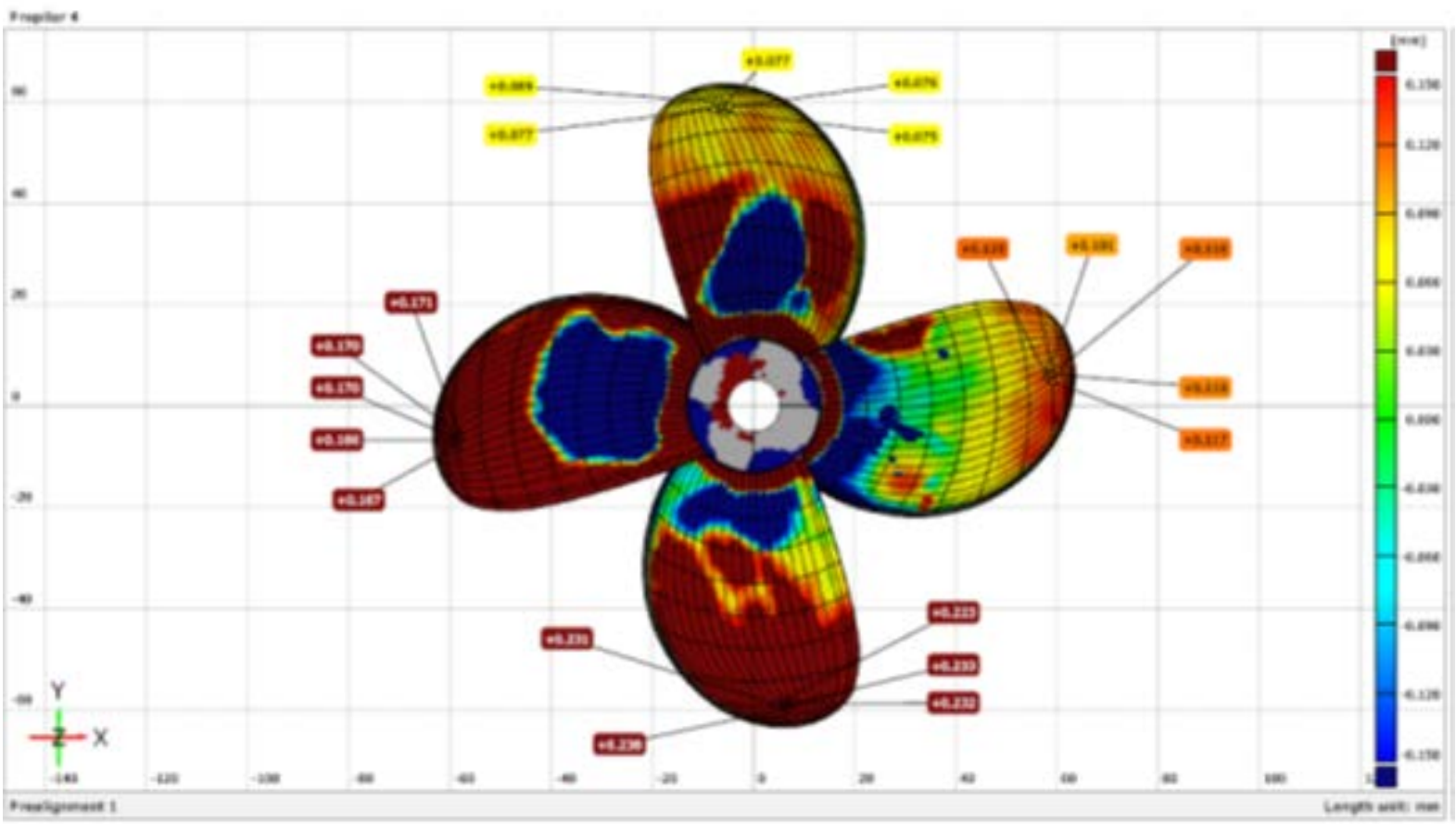

Fig. 9. Deviation contour for position measurement \#1 on the front side of the blade propeller for variations in feed-rate parameters

Propelier 4 Front Side

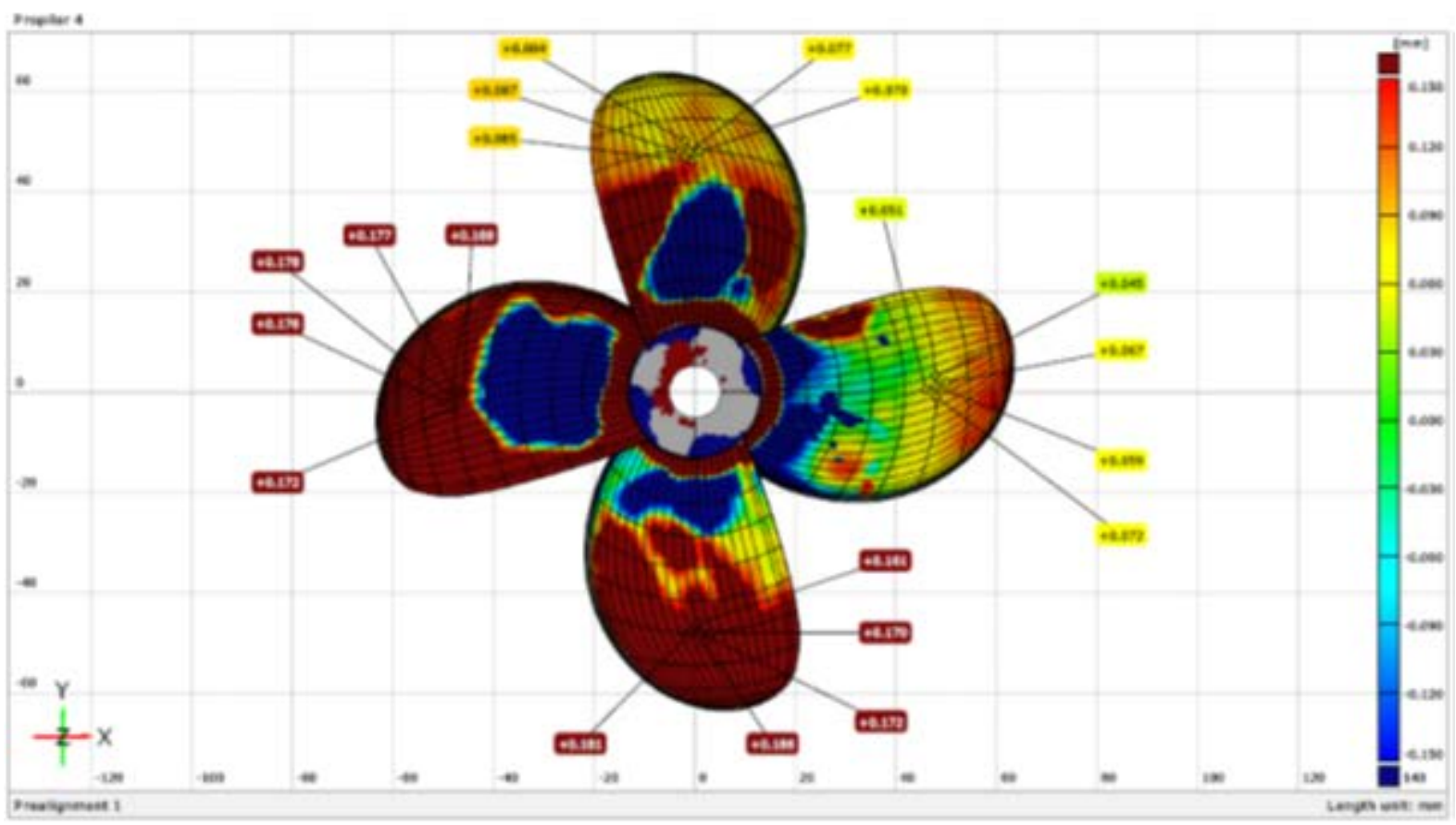

Fig. 10. Deviation contour for position measurement $\# 2$ on the front side of the blade propeller for variations in feed-rate parameters 